\title{
INCORPORATING DIFFERENT SOURCE RUPTURE CHARACTERISTICS INTO SIMULATIONS OF STRONG GROUND MOTION FROM THE 1867, M7.0 EARTHQUAKE ON THE ISLAND OF LESVOS (NE AEGEAN SEA, GREECE)
}

\author{
Roumelioti Z. ${ }^{1}$ and Kiratzi A. ${ }^{2}$ \\ ${ }^{1}$ Archaeologikou Mouseiou 46, 54641 Thessaloniki, Greece, zroum@auth.gr \\ ${ }^{2}$ Department of Geophysics, Aristotle University of Thessaloniki, P.O. Box 352-1 Thessaloniki, \\ Greece,Kiratzi@geo.auth.gr
}

\begin{abstract}
We apply the stochastic method for finite-faults (Beresnev and Atkinson, 1997, 1998) to simulate strong ground motion acceleration from the 1867 earthquake that devastated the Island of Lesvos in NE Aegean Sea. Recent geological data are taken into account to construct realistic models of the earthquake source, while a first-order approximation of the site effect variation throughout the entire island of Lesvos is achieved following an empirical approach suggested by Wald and Allen (2007). We test several source models including different segments of the Agia Paraskevi fault, which is most probably the seismogenic fault of the 1867 earthquake. Stronger ground motion is predicted in the central part of the island, i.e. around the assumed seismogenic structure. A significant site effect is evident along the eastern coast of Lesvos, where the capital of Mytilene lies, strongly hit by the 1867 earthquake, and around the gulfs of Kalloni and Geras in the south and southeast parts of the island. Synthetic peak ground acceleration values are converted to macroseismic intensities through an empirical relation and discussed in comparison with available reports on the macroseismic effects of the 1867 earthquake.
\end{abstract}

Key words: strong ground motion, Lesvos, simulation.

\section{Introduction}

A recent approach to study historical earthquakes is based on modelling the available macro-seismic data by simulating the seismic wave field (e.g. Zollo et al., 1999; Emolo et al., 2004). To do so, one has to start from one or more source models available in the literature, compute synthetic time histories of strong ground motion, extract appropriate peak values, usually of engineering interest, convert them to intensities through empirical relations and discuss the results in terms of differences between synthetic data and observations. The ultimate goal is to better understand destructive historical earthquakes and thus to improve the ability to predict scenarios that will help planners and decision makers to prepare for the next event.

In the present work we adopt the aforementioned approach to study the most destructive event in the known earthquake history of the Island of Lesvos in North Aegean Sea, the M7.0 (Papazachos and Papazachou, 2003) earthquake of March 1867. 


\section{The 1867 earthquake}

The event or rather a sequence of at least four strong events (most probably one foreshock, the mainshock and two strong aftershocks), spaced closely in time, occurred on the afternoon (6 p.m. local time) of March 7, 1867. It caused severe shaking of the entire Island of Lesvos and was felt as far away as in central Greece, Çanakalle and Izmir in western Turkey. Most scientists place the epicenter of the earthquake somewhere in the central part of Lesvos, where the maximum macroseismic intensity values were reported (IX-X in Kloumidados village which was later named as NapiFig. 1; Kampouris, 1978; Ambraseys and Finkel, 1995; Papazachos and Papazachou, 2003).

Although its dramatic impact established the 1867 earthquake as a turning point in the history of the Island of Lesvos accurate records on the fatalities and damage it caused are absent from official archives (Kampouris, 1978 and references therein). We do know that hundreds of people were killed in Mytilene, the capital of the island, in villages in the central part of the island and in villages around the Gulf of Geras, to the S-SW of Mytilene. The exact number of fatalities ranges from about 600 to more than 1000 , while the corresponding numbers for injured people range from few hundreds to more than 2000. Most villages, especially at the central and eastern parts of Lesvos were either completely or partly destroyed.

Even back in the time of the 1867 earthquake scientists related the distribution of damage on Lesvos to the variability of the surface geology, hence the site effects. According to a geology expert who was sent to Lesvos as a delegate of the French government (Kampouris, 1978), the impact of the earthquake was dramatic in the central part of the island which is covered by volcanic rocks, lighter in the eastern part of the island where schist and marble dominate the surface geology and almost inexistent in the SE part of Lesvos which is covered by ophiolites (mountainous area between Polichnito and Agiasos in Fig. 1). Great damage was also observed in villages around the gulfs of Geras and Kalloni, which were situated on recent loose deposits. Local scientists also note (Kampouris, 1978) that the dramatic consequences of the earthquake within the capital of the island, Mytilene, were due to the fact that the central market (where most severe damage was observed) was sited on the ruins of the ancient city of Evripos as well as to the very poor quality of the structures.

Most catastrophic historical earthquakes on the island of Lesvos, as well as the 1867 event, have been related to the Agia Paraskevi - Kalloni fault (Papazachos and Papazachou, 2003), a NNE-SSW trending right-lateral strike-slip structure which cuts across the island. This structure consists nowadays the predominant tectonic feature on Lesvos. Its segments on the island's surface and its probable continuation within the Gulf of Kalloni are shown in Figure 1 (as suggested by Pavlides et al., 2008).

\section{Simulation of Strong Ground Motion}

\subsection{Method}

Strong ground motions were simulated using the FINSIM code of Beresnev and Atkinson (1998). This code implements the stochastic strong ground motion simulation technique for finite earthquake sources (Beresnev and Atkinson, 1997, 1998), which is based on the pioneering work of Boore (1983). Detailed description of the method is given in the aforementioned references.

\subsection{Model}

The applied technique requires modeling of the three fundamental effects that shape strong ground motion: the source, the attenuation along the propagation path of the seismic waves and the local site 


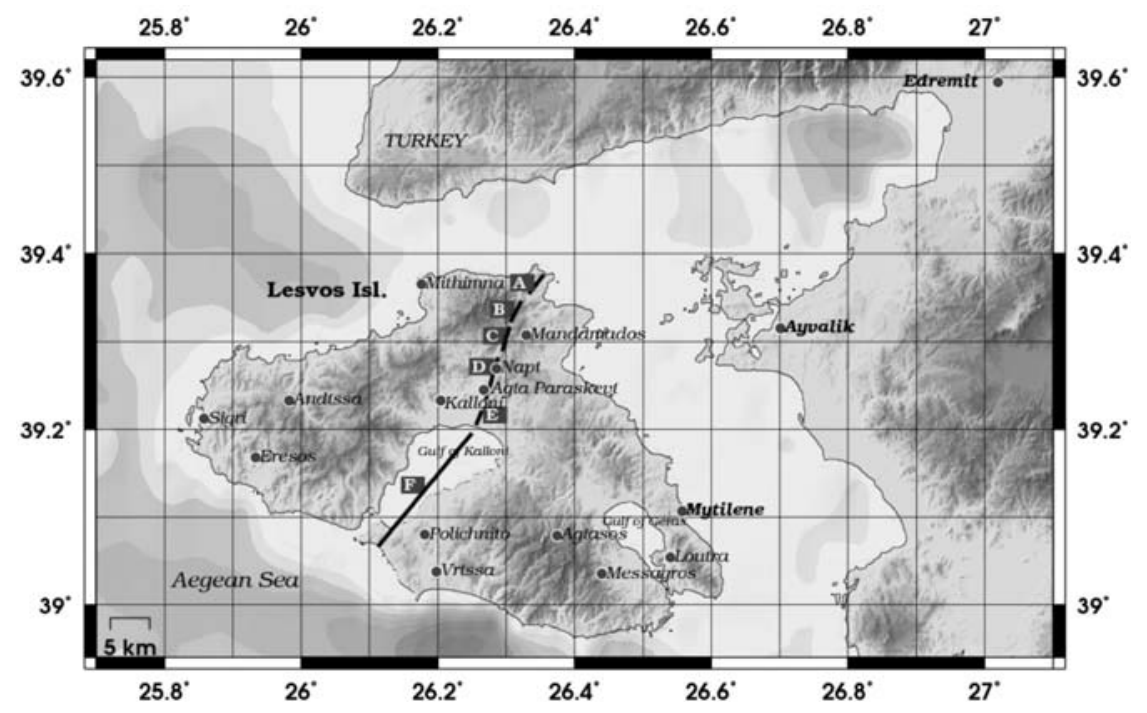

Fig. 1: Segments of the Agia Paraskevi - Kalloni fault as suggested by Pavlides et al. (2008).

conditions at the site of interest (observation/simulation points). Basic modeling parameters for each one of these effects are described in the following.

Propagation Path: Parameterization of the propagation path includes empirical description of the geometric attenuation and the anelastic attenuation of the seismic waves. For the geometric attenuation we applied a geometric spreading operator of $1 / R$, where $R$ is the distance from the seismic source, while the anelastic attenuation was described through a frequency-dependent quality factor, $Q(f)=100 f^{0.8}$, applicable to the broader Aegean area (Hatzidimitriou, 1993, 1995).

Near-surface attenuation of the seismic waves was modeled using the kappa, $\varkappa$, operator of Anderson and Hough (1984) and diminishing the simulated spectra by $\exp (-\pi x f)$. Simulations at all sites of interest were performed assuming rock site conditions at the ground surface. The value for the kappa operator for rock adopted herein is the one proposed by Margaris and Boore (1998).

Site Effects: In the present work, which aims to produce a picture of the distribution of strong ground motion throughout the entire Island of Lesvos, we do not include detailed information on the site effect variation. To our knowledge, such information is not available. However, we attempt a first-order incorporation of the site effect in our final strong ground motion parameters distribution maps following an empirical approach suggested by Wald and Allen (2007). In the aforementioned study it is shown that there is correlation between the slope of the topography of a region and the $\mathrm{V}_{\mathrm{S} 30}$ (average shear-wave velocity at the top 30 meters of the soil column) values, which are often used to characterize the site effect. Wald and Allen (2007) proposed a global database of topographic-slope based $\mathrm{V}_{\mathrm{S} 30}$ which can be used to derive first-order site-condition maps when geotechnical site-specific data are insufficient or inexistent. Part of the original $\mathrm{V}_{\mathrm{S} 30}$ database, which covers the area of interest in the present study, was re-sampled using the spatial interval of the strong motion simulations grid $\left(0.01^{\circ}\right)$ and each grid point was assigned a $\mathrm{V}_{\mathrm{S} 30}$ value. Based on this value and the amplitude of the peak ground acceleration in the synthetic accelerogram at the corresponding grid point we selected an appropriate empirical amplification factor for the PGA following the suggestion of Borcherdt (1994). 
Source: Modeling of the 1867 earthquake source was primarily based on the available neotectonic information and geological mapping of the Agia Paraskevi - Kalloni structure. The segments of the fault, as have been recently described in Pavlides et al. (2008) are shown in Figure 1. Within the frame of the present work we tested several rupture scenarios by combining different mapped segments and several locations of the rupture initiation point on each fault model surface. Due to space limitations we cannot show results from all tested cases. However, we summarize in the following section our basic conclusions from the comparative examination of resulting PGA distributions and present our preferred scenario. The last one involves surface rupture along segments E, D, C and B (Figure 1) i.e. a total length of approximately $16.5 \mathrm{~km}$ (the surface projection of the fault model is mapped in Figure 2). The documented length of the surface expression of the 1867 earthquake is 3$7 \mathrm{~km}$ although it is likely that it continues offshore (Pavlides et al., 2000). In any case, we believe that our scenario surface rupture length surpasses that of the 1867 event. Based on this length and appropriate empirical relations (Wells and Coppersmith, 1994; Pavlides and Caputo, 2004) the moment magnitude of the scenario event is M 6.5-6.6.

Although we do not know the rupture propagation characteristics of the studied event it is possible to place the rupture initiation point on the model surface following rules that are based on the international seismological experience. Regarding the depth of the hypocenter (assumed to coincide with the rupture initiation point in FINSIM) we know that most large magnitude strike-slip earthquakes nucleate close to either the fault base or the fault's half width (e.g. Somerville et al., 1999; Manighetti et al., 2005, Mai et al., 2005). Thus, in our fault model, which includes three sub-faults along dip, a realistic location of the hypocenter is on the deepest (third) sub-fault. Rupture propagation is more difficult to be realistically modeled. However, in the case of the 1867 event it is most probable that rupture propagated unilaterally toward NNE. This scenario is favored both by earthquake statistics (McGuire et al., 2002; Manighetti et al., 2005) and the reported damage of the 1867 event in western Turkey (e.g. in Ayvalik and Edremit).

\subsection{Results}

As mentioned above we tested numerous rupture scenarios regarding the source dimensions of the 1867 event and the location of the rupture initiation point (controlling basically the directivity of the rupture). Our basic conclusions from the comparative study of their resulting PGA distribution patterns are summarized in the following.

The total, sub-surface length of the fault model in our preferred scenario (Figure 2) does not exceed $30 \mathrm{~km}$, while its surface expression length is $16.5 \mathrm{~km}$ as discussed in the previous section. Both lengths were determined by the employed empirical relations (see section 3.2). When larger source dimensions were introduced in simulations (and, thus, larger earthquake magnitude) synthetic PGA values in the west part of Lesvos were too high to explain the fact that most villages in that area remained intact by the examined historical event.

The addition of segment A (Figure 1) in the surface rupture of the 1867 fault model does not change the resulting PGA distribution pattern in any significant way and as there were no documented surface brakes along it we chose not to introduce it in our simulations.

The rupture of segment $\mathrm{F}$ increases the strong motion level in the northeastern part of Lesvos and most importantly toward the Turkish town of Ayvalik and Edremit, which suffered significant damage from the 1867 earthquake. However it cannot explain the low degree of damage within the valley of Troy in western Anatolia ( $>60 \mathrm{~km}$ to the north of Lesvos Isl.), which is located along the strike 

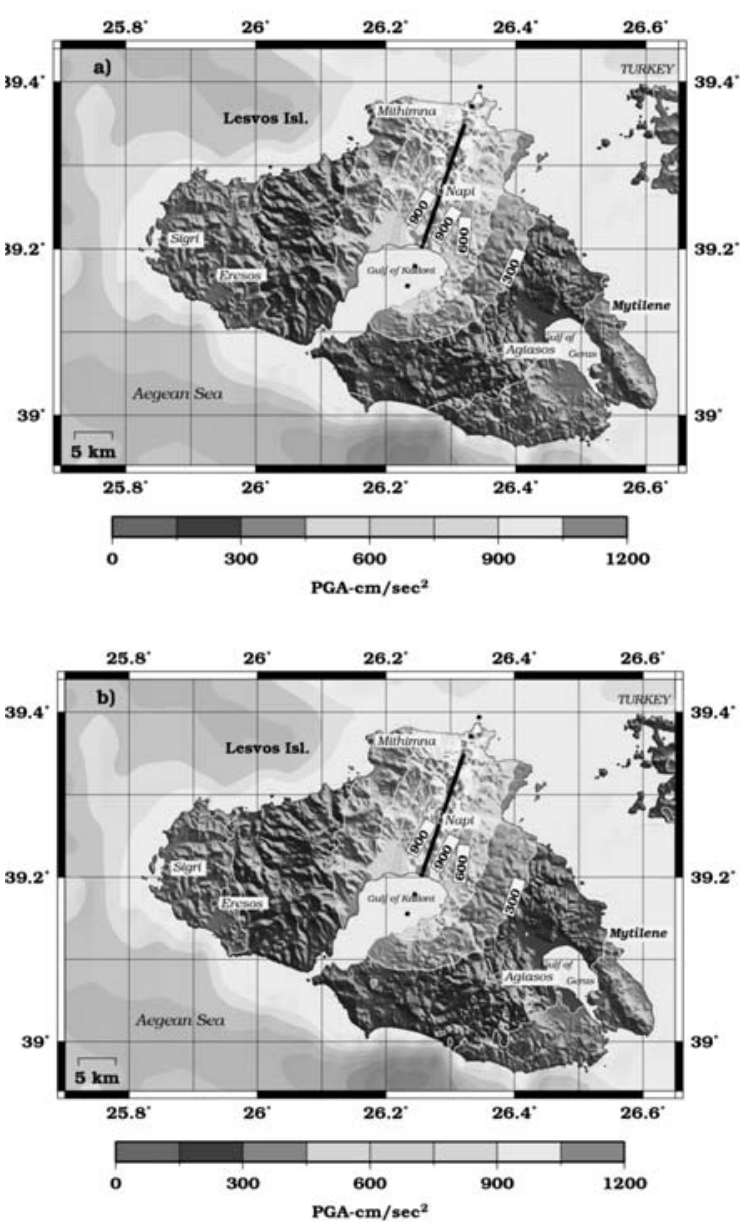

Fig. 2: Synthetic PGA distribution map (contoured in units of $\mathrm{cm} / \mathrm{sec}^{2}$ ) for a scenario earthquake of M6.5 on the Agia Paraskevi zone. The surface projection of the adopted fault model is shown by a black line (continuous where surface rupture is allowed and dotted elsewhere) a) Plotted values correspond to surface geological conditions corresponding to rock $\mathrm{b}$ ) synthetic values after the gross incorporation of the site effect (see text).

of the on-land segments of the Agia Paraskevi fault. Similar increase in PGAs toward NNE is achieved if the on-land segments are ruptured up to the surface and the hypocenter is located in the southern part of the fault model (i.e. introduce rupture directivity toward the north).

In Figure 2 we map the distribution of synthetic PGA values as derived from the application of the finite-fault stochastic strong ground motion simulation technique (spacing in simulation grid was $0.01^{\circ}$ ) in the case of our preferred model (described in the previous section). Our preferred source model places the surface rupture of the 1867 seismogenic fault in the central part of Lesvos, starting from the Gulf of Kalloni and extending along a NNE-SSW direction in accordance with historical information. It provides realistic synthetic PGA values on the Island of Lesvos and directivity effects toward western Turkey.

In Figure 2a we plot the synthetic values as were computed for surface site conditions corresponding to rock (site category B; Margaris and Boore, 1998; Klimis et al., 1999) and in Figure 2b we plot the corresponding values after the empirical corrections for the amplification of the local geology and non-linear response of soil (Borcherdt, 1994). In general, the effect of the empirical correction to introduce the site response is rather small; however an increase in synthetic PGA values 


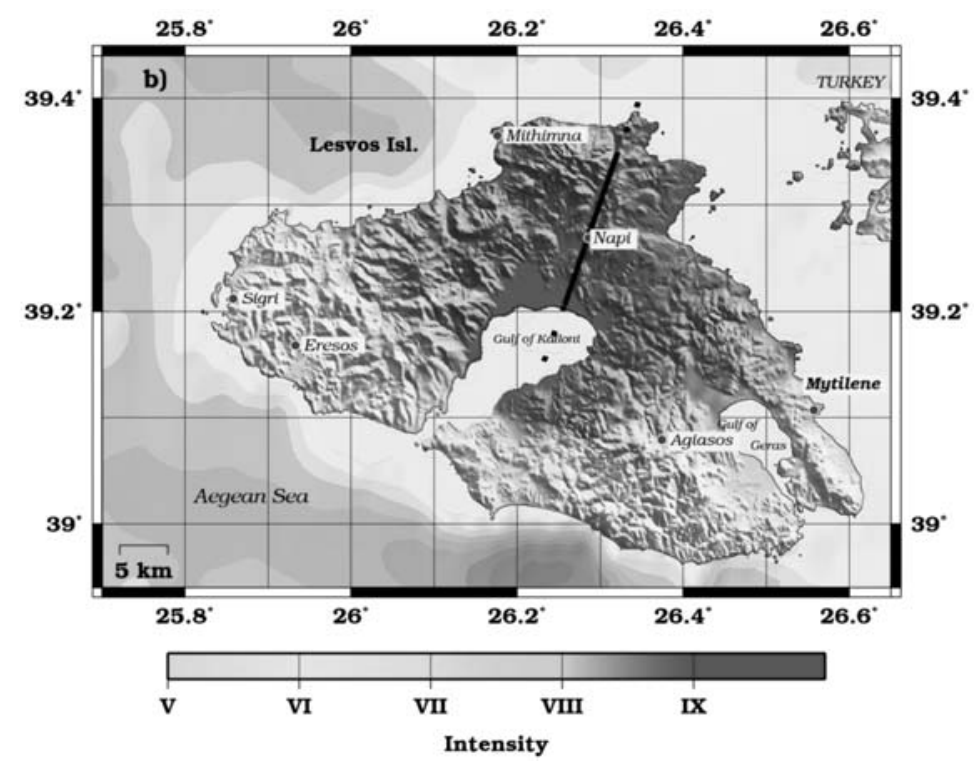

Fig. 3: Synthetic Modified Mercalli Intensity (MMI) map for the 1867 earthquake. The surface projection of the adopted fault model is shown as a black line (continues where surface rupture is allowed and dotted elsewhere).

is evident in the SE part of the island and more specifically around the Gulf of Geras and along the SE coast where the heavily damaged capital of Mytilene lies. Thus, even a rough incorporation of the site amplification manifests that local site conditions were among the important factors that shaped the strong ground motion distribution pattern.

Overall, the strongest ground motion is predicted along the adopted fault trace with PGA values that exceed $1 \mathrm{~g}$ at several simulation points. Such large values are indicative of the strength of the shaking in the near-fault area. However, the distribution of strong ground motion at such close distances from the source greatly depends on the rupture characteristics of the earthquake and its slip distribution pattern, factors that cannot be realistically modelled for an historical earthquake. In any case, the simulated motions are extremely strong in accordance with the reported devastation of villages in this area and the location of the macroseismic epicentre by a number of researchers (Kampouris, 1978; Ambraseys and Finkel, 1995; Papazachos and Papazachou, 2003).

High PGA values around the Gulf of Kalloni, where many villages were destroyed by the 1867 event are due to the location and orientation of the fault model. In this area, the proximity to the seismogenic source appears to be the prevailing factor in the shaping of strong ground motion. The effect of soft soil formations along the coastline is masked by the strong source effect.

The placement of the hypocenter location in the SSW part of the fault model and thus the directivity of the rupture propagation to the NNE causes the asymmetry in the PGA distribution towards the coast of western Turkey.

To convert synthetic PGA values to Macroseismic Intensities (herein intensity values are in the Modified Mercalli scale, MMI) so as to be comparable to historical damage information we used the empirical relations of Atkinson and Sonley (2000). Although such relations based on data from Greek earthquakes are available in the literature (Theodulidis and Papazachos, 1992; Koliopoulos 
et al., 1998; Tselentis and Danciu, 2008) they are all based on the epicentral distance which in the case of the 1867 is much less constrained compared to the closest-to-the-fault distance required in Atkinson and Sonley (2000). Results are mapped in Figure 3. Synthetic intensities are quite high throughout the entire surface of the island with values being larger than IX in its central part. The heavily damaged capital of Mytilene lies within the VIII-IX intensity zone, both because of its small distance from the seismogenic source and the site effect of the soft soils close to the coastline. Following the PGA distribution pattern of Figure $2 \mathrm{~b}$ synthetic intensities are increased by approximately one unit around the Gulf of Geras. To the west of the island (Sigri, Eresos) intensities drop below VI and that explains the absence of significant damage as reported in historical documents.

The synthetic MMI of Figure 3 compare quite well to the map of isoseismals of Papazachos et al. (1997) although the area covered by the aforementioned map is much larger $\left(37^{\circ} \mathrm{N}, 22^{\circ} \mathrm{E}-42^{\circ} \mathrm{N}\right.$, $\left.31^{\circ} \mathrm{E}\right)$. For the Island of Lesvos and the neighbouring western coast of Turkey Papazachos et al. (1997) suggest intensities of VIII-X and VII-VIII respectively, which are similar to those proposed in the present work.

\section{Conclusions}

The destructive 1867 earthquake on the Island of Lesvos was studied by examining several rupture scenarios, simulating the strong ground motion throughout the entire island and comparing synthetic values to available macroseismic information. Among the tested scenarios our preferred one includes surface rupture on four on-land mapped segments (B-E in Figure 1) of the Agia Paraskevi fault, rupture initiation on the southern part of the fault model and thus directivity toward NNE.

The simulated earthquake magnitude is M 6.5 i.e. significantly smaller compared to the value of 7.0 inferred by processing of historical macroseismic intensities (Papazachos et al., 1997; Papazachos and Papazachou, 2003). However, examination of larger magnitude earthquake scenarios result in very high PGA values in the west part of Lesvos, which contradict the documented absence of damage in this area. A smaller magnitude is also predicted by empirical relations (Wells and Coppersmith, 1994; Pavlides and Caputo, 2004) based on the surface rupture length inferred by historical data. Even if we consider the scientific finding of Pavlides and Caputo (2004) that co-seismic fault rupture lengths in the Aegean Sea and neighbouring lands have systematically lower values compared to similar parameters in the world-wide database (e.g. in those consisting the basis for the herein adopted empirical relations of Wells and Coppersmith, 1994) and use a much larger surface rupture length than the one documented (in our simulations we used $16.5 \mathrm{~km}$ compared to 3-7 km reported in historical archives) the magnitude of the simulated event is not larger than M 6.6. This discrepancy may be due to the fact that the magnitude evaluations based on historical macroseismic data inherently include the effect of lower vulnerability of the structures in the time of the event occurrence.

The contribution of site effects in the distribution of PGAs, although they are only grossly incorporated in our simulations, is evident in the synthetic maps; increased levels of shaking are predicted along the east coast of Lesvos and around the gulfs of Kalloni and Geras. However, the combinational effect of high vulnerability of the structures of that time is still required to explain the devastation of Mytilene.

\section{Acknowledgments}

We thank Dr. A. Chatzipetros, MSc S. Sboras and Prof. S. Pavlides of the Department of Geology of the Aristotle University of Thessaloniki for geological information on the 1867 seismogenic fault. Maps 
were produced using the GMT software (Wessel and Smith, 1998). This work was funded by the General Secretariat of Research and Development of Greece (PEP-NAEGEAN).

\section{References}

Ambraseys, N. N., and Finkel, C. F., 1995. The seismicity of Turkey and adjacent areas, Publ. Eren Ltd., Istanbul, pp. 240.

Anderson, J. G., and Hough S. E., 1984. A model for the shape of the Fourier amplitude spectrum of acceleration at high frequencies, Bull. Seism. Soc. Am. 74, 1969-1993.

Atkinson, G. M., and Sonley E., 2000. Empirical Relationships between Modified Mercalli Intensity and Response Spectra, Bull. Seism. Soc. Am. 90(2), 537-544.

Beresnev, I. A., and Atkinson G. M., 1997. Modeling finite-fault radiation from the $\omega^{n}$ spectrum, Bull. Seism. Soc. Am. 87, $67-84$.

Beresnev, I. A., and Atkinson G. M., 1998. FINSIM - a FORTRAN program for simulating stochastic acceleration time histories from finite faults, Seism. Res. Lett. 69, 27 - 32.

Borcherdt, R. D., 1994. Estimates of site-dependent response spectra for design (methodology and justification), Earthquake Spectra 10, 617- 653.

Boore, D. M., 1983. Stochastic simulation of high-frequency ground motions based on seismological models of the radiated spectra, Bull. Seism. Soc. Am. 73, $1865-1894$.

Emolo A., Iannaccone G., Zollo A., Gorini A., 2004. Inferences on the source mechanisms of the Irpinia (Southern Italy) earthquake from simulations of the kinematic rupture process, Annals of Geophysics 47, 1743-1754.

Hatzidimitriou, P. M., 1993. Attenuation of coda waves in Northern Greece, Pure and Appl. Geophys. 140, $63-78$.

Hatzidimitriou, P. M., 1995. S-wave attenuation in the crust in Northern Greece, Bull. Seism. Soc. Am. 85, $1381-1387$.

Kampouris, Z. P., 1978. Calamities in Lesvos in the $19^{\text {th }}$ century, Publ.J.A. Paspate, Mytilene pp. 77 (in Greek).

Klimis, N. S., Margaris, B. N. and Koliopoulos, P. K., 1999. Site dependent amplification functions and response spectra in Greece, Journal of Earthquake Engineering 3, 237 - 247.

Koliopoulos, P. K., Margaris, B. N., and Klimis, N. S., 1998. Duration and energy characteristics of Greek strong motion records, J. Earthq. Eng. 391-417.

Mai, P.M., Spudich, P., and Boatwright J., 2005. Hypocenter locations in finite-source rupture models, Bull. Seism. Soc. Am. 95(3), 965-980.

McGuire, J. J., Zhao, L., and Jordan, T. H., 2002. Predominance of unilateral rupture for a global catalog of large earthquakes, Bull. Seism. Soc. Am. 92,3309- 3317.

Manighetti, I., Campillo, M., Sammis, C., Mai, P.M., and King G., 2005. Evidence for self-similar, triangular slip distributions on earthquakes: Implications for earthquake and fault mechanics, J. Geophys. Res. 110.

Margaris, B. N., and Boore D. M., 1998. Determination of $\Delta \sigma$ and $x_{0}$ from response spectra of large earthquakes in Greece, Bull. Seism. Soc. Am. 88, 170 - 182.

Papazachos, B. C., Papaioannou, Ch. A., Papazachos, C. B., and Savvaidis, A. A., 1997. Atlas of isoseismal maps for strong earthquakes in Greece and surrounding area, Publ. Geoph. Lab. Univ. Thessaloniki, 4, pp 200.

Papazachos, B. C., and Papazachou C., 2003. The earthquakes of Greece, Ziti Publ. Co., Thessaloniki, 
Greece, pp. 286 (in Greek).

Pavlides, S., and Caputo, R., 2004. Magnitude versus faults' surface parameters: quantitative relationships from the Aegean region, Tectonophysics 380, 159-188.

Pavlides, S., Caputo, R., and Chatzipetros, A., 2000. Empirical relationships among earthquake magnitude, surface ruptures and maximum displacement in the broader Aegean region, Proc. of the $3^{\text {rd }} \mathrm{In}$ ternational Conf. on the Geology of the Eastern Mediterranean, eds. Panayides, I. and Xenophontos C.

Pavlides et al., 2008. Identification of active tectonic structures using geologic data, Report included in the final report of the project "Contribution of advanced methods of Geosciences in seismic risk management with emphasis to the built environment of the North Aegean Sea Islands" funded by General Secretariat of Research and Technology, [PEP-NAEGEAN], 2006 - 31.05.2008.

Somerville, P., Irikura, K., Graves, R., Sawada, S., Wald, D., Abrahamson, N., Iwasaki, Y., Kagawa, Smith, N., and Kowada A., 1999. Characterizing crustal earthquake slip models for the prediction of strong ground motion, Seism. Res. Let. 70, 59-80.

Theodulidis, N. P., and Papazachos, B. C., 1992. Dependence of strong ground motion on magnitude-distance, site geology and macroseismic intensity for shallow earthquakes in Greece: I, peak horizontal acceleration, velocity and displacement, Soil Dyn. Earthq. Eng. 11, 387-402.

Tselentis, G.-A., and Danciu L., 2008. Empirical relationships between Modified Mercalli Intensity and Engineering Ground-Motion Parameters in Greece, Bull. Seism. Soc. Am. 98(4), 1863-1875.

Zollo A., Emolo A., Herrero A., Improta L., 1999. High frequency strong motion modelling in the Catania area associated with Ibleo-Maltese fault system, J. Seismology 3, 279-288.

Wald, D. J., and Allen T. I., 2007. Topographic slope as a proxy for seismic site conditions and amplification. Bull. Seism. Soc. Am. 97(5), pp. 1379-1395, doi: 10.1785/ 0120060267.

Wells, D. L., and Coppersmith, K. J., 1994. New empirical relationships among magnitude, rupture length, rupture width, rupture area and surface displacement, Bull. Seism. Soc. Am. 84, 974-1002.

Wessel, P., and Smith, W.H.F., 1998. New improved version of the Generic Mapping Tools released. EOS Trans. AGU 79, 579. 